\title{
Extra-axial Cerebellopontine Angle Adult Medulloblastoma: An Unusual Presentation at an Unusual Site
}

\author{
Vishwaraj Ratha ${ }^{1}$ Vikram S. Karmarkar ${ }^{2} \quad$ Chandrashekhar E. Deopujari ${ }^{3}$ \\ ${ }^{1}$ Department of Neurosurgery, SRM Institute of Medical Sciences, \\ Vadapalani, Chennai, Tamil Nadu, India \\ 2Department of Neurosurgery, Bombay Hospital Institute of \\ Medical Sciences and Research Center, Mumbai, Maharashtra, India \\ Address for correspondence Vishwaraj Ratha, MBBS, MS, Mch, \\ Department of Neurosurgery, SRM Institute of Medical Sciences, \\ 100 Feet Road, Jawaharlal Nehru Salai, Vadapalani, Chennai, Tamil \\ Nadu, India, Pin code 600026 (e-mail: thinkvishwaraj@gmail.com).
}

${ }^{3}$ Department of Neurosurgery, Bombay Hospital Institute of

Medical Sciences and Research Center, Mumbai, Maharashtra, India

Indian J Neurosurg 2019;8:203-206

\begin{abstract}
Keywords

- cerebellopon-

tine angle

medulloblastoma

- extra-axial

- differential diagnosis

- adult
\end{abstract}

\section{Introduction}

The term medulloblastoma cerebelli was coined in 1925 for poorly differentiated cerebellar tumors by Bailey and Cushing. ${ }^{1}$ It is the most common childhood intracranial tumor, accounting for $25 \%$ of all pediatric intracranial tumors and $33 \%$ of all posterior fossa neoplasm in children. ${ }^{1}$

In adults, the tumor is uncommon, accounting for approximately $1 \%$ of adult primary brain tumors and $6 \%$ of posterior fossa tumors, $80 \%$ of which occur before the end of the fourth decade. ${ }^{1,2}$ The incidence of adult Medulloblastoma is approximately 0.5 per million per year and decreases with increasing age. The published studies on adult medulloblastoma are usually retrospective, owing to its rarity in adult populations, and are mostly midline (cerebellar vermis)., ${ }^{1,2}$

We report an extremely rare occurrence of adult cerebellopontine angle (CPA) medulloblastoma. This case underlines the existence of the extremely rare intra-axial adult tumor in this unusual location, mimicking as a purely extra-axial lesion, thereby confounding its diagnosis. It also demonstrates the difficulties encountered when relying on an imaging diagnosis for medulloblastoma, especially in adults. There are only 40 reported cases of CPA medulloblastoma in the literature, with most being intra-axial. ${ }^{2-5}$ Extra-axial CPA medulloblastoma is extremely rare and only 10 adult cases have been reported in world literature. ${ }^{6}$

\section{Case Report}

A 42-year-old female patient presented with complaints of progressive headache and ataxia over a duration of 2 months. On neurological examination, her vision was normal with no papilledema. She had no cranial nerves deficit or any other focal neurological deficit, except for left cerebellar signs and

\section{received}

March 22, 2018

accepted

May 16, 2018

published online

October 22, 2019
DOI https://doi.org/

$10.1055 / \mathrm{s}-0039-1698481$

ISSN 2277-954X.
C2019 Neurological Surgeons'

Society of India
License terms

() (1) $\ominus \circledast$ 
nystagmus. Magnetic resonance imaging (MRI) showed a heterogeneous lesion more hypo-intense than the gray matter on T1-weighted images (T1WIs) and hyper intense on T2-weighted images (T2WIs) (-Fig. 1A). There was heterogeneous enhancement of lesion after administration of contrast. Axial and coronal imaging revealed the attachments of lesion to the left posterior petrosal dura and inferior surface of tentorium. On corelating the preoperative clinical and radiological findings, the common extra-axial CPA tumors, such as meningioma and acoustic neuroma, were considered as differential diagnoses.

She underwent a standard retromastoid approach and the lesion was exposed through the left CPA. The lesion was grayish white and solid but soft and friable in consistency also, easily suckable. There was a clear plane between the tumor and cerebellum; however, it was also adherent to dura and tent laterally. We could achieve a complete excision of tumor. Hence, our intraoperative inference was that of an extra-axial soft dural based tumor, probably meningioma. Her postoperative period was uneventful. She had no focal neurological deficit and her cerebellar signs also gradually improved. The postoperative CT scan revealed no definite residual or recurrent mass ( $\mathbf{- F i g . 1 B}$ ).

However, the histopathology (HP) showed a highly cellular tumor composed of rosettes of small round cells, with high nucleus-cytoplasm ratio and increased mitotic figures-suggestive of classical medulloblastoma-WHO grade IV (-Fig. 2A). Immunohistochemical study revealed synaptophysin, S-100 protein, and neuron-specific enolase to be positive but GFAP, neurofilament, and cytokeratin were negative (-Fig. 2B).

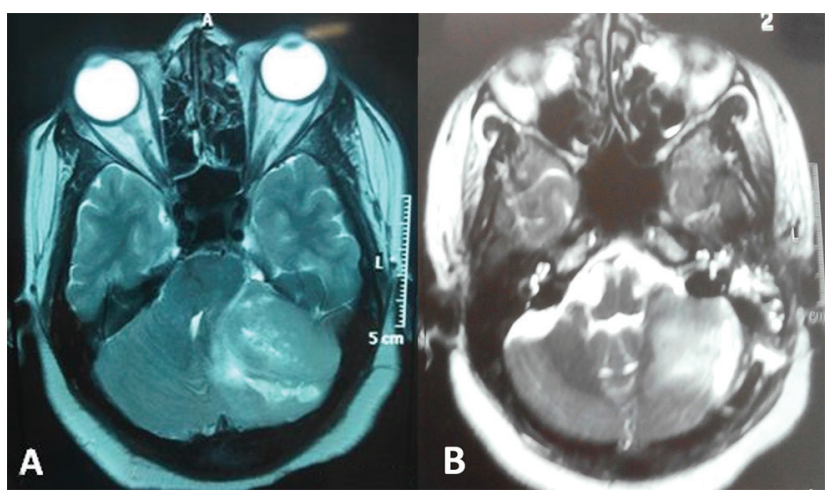

Fig. 1 (A) Preoperative MRI brain hyperintense on T2W axial. (B) Postoperative MRI brain showing complete excision of the tumor.

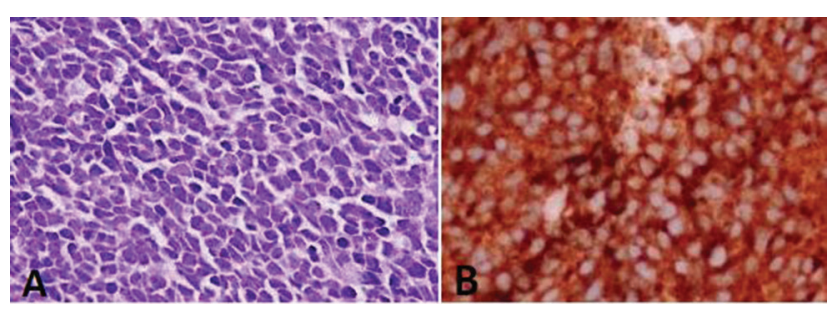

Fig. 2 (A) H\&E: Classic medulloblastoma showing a diffuse pattern of tumor growth with poor cellular differentiation, nuclear molding, and minimal indistinct cytoplasm (B) IHC: Synaptophysin positivity in medulloblastoma shows as a brown staining of the cells.
In view of the histopathological diagnosis being contrary to our preoperative impression, the specimens were reviewed again by a second pathologist, but the diagnosis remained the same.

After the HP result was reported, MRI of the spinal cord was performed and it revealed no evidence of metastasis to the spinal cord. The patient underwent cranio-spinal radiotherapy. Magnetic resonance images obtained 3 months postoperatively demonstrated no residual or recurrent mass. She has been under regular follow-up for 15 months with no recurrences or metastases yet.

\section{Discussion}

In 2007, WHO designated it as a distinct embryonal tumor, distinguishing it from other primitive neuroectodermal tumors (PNETs). ${ }^{2}$ Medulloblastoma is predominantly a pediatric tumor accounting for one-fourth of all pediatric intracranial tumors. The most common site is the cerebellar vermis, from where it penetrates the fourth ventricle, resulting in abnormalities in the flow of cerebrospinal fluid (CSF). In 10 to $30 \%$ of pediatric cases, it has been observed to spread along the CSF routes and become disseminated within the central nervous system. The radiological features of medulloblastoma are classical: they display an iso- or hypointense signal on T1WI, are heterogeneous on T2WI, and exhibit homogeneous enhancement after addition of gadolinium, sometimes demonstrating a central hemorrhagic zone (our preoperative diagnosis of CPA meningioma was due to age of the patient at presentation and imaging features of well-demarcated, broad-based, extra-axial, homogenously contrast-enhancing lesion). Medulloblastoma in adults is an uncommon entity ( $1 \%$ of adult primary brain tumors) and its presence in $\mathrm{CP}$ angle region is exceptionally rare. There have been only 10 reported cases of extra-axial medulloblastoma in the adult literature. ${ }^{6}$ The table describes CPA medulloblastomas described in the past, presentation, management, and outcome compared to the present case (-Table 1); however, they are likely to be underreported owing to publication bias. This tumor is nearly twice as common in men. The tumors most often occur among patients in their late 20s and early 30s. ${ }^{6}$ It has been observed that the two most common sites for extra-axial locations are the tentorial and CPA regions., ${ }^{3,6-12}$ Most commonly, they manifest as heterogeneously enhancing lesions upon contrast administration.

There are currently two general hypotheses regarding the origin and spread of medulloblastoma. In the first, medulloblastomas are proposed to arise from primitive multipotential cells in the external granular cell layer in the cerebellar hemisphere, mainly the flocculus which faces the $\mathrm{CPA}$. The alternative view is that medulloblastomas arise from multipotential cells in the subependymal region and within the fetal pineal region, giving rise to all PNETs, regardless of location. ${ }^{1}$ In other words, medulloblastoma can occur anywhere (including CPA) along the germ cell tumors' normal migration course to lateral side. ${ }^{1,13}$

In our case, both the preoperative and intraoperative findings pointed toward an entirely extra-axial tumor 
Table 1 List of various CPA medulloblastomas described in the past, the presentation, course of management, and follow-up

\begin{tabular}{|c|c|c|c|c|c|}
\hline Author and year & Age and sex & $\begin{array}{l}\text { Duration of } \\
\text { symptoms }\end{array}$ & Presentation & Treatment & Follow-up \\
\hline Becker et al $1995^{10}$ & $32 \mathrm{~F}$ & - & $\mathrm{H}, \mathrm{NV}$ & - & - \\
\hline Akay et al $2003^{15}$ & $21 \mathrm{M}$ & 2 months & $\begin{array}{l}\mathrm{H}, \mathrm{V} \text {, ataxia, B/L PE, HP, } \\
\mathrm{HA}\end{array}$ & $\mathrm{PE}, \mathrm{CT}, \mathrm{RT}$ & 18 months \\
\hline Gil Salu et al, $2004^{9}$ & $40 \mathrm{M}$ & - & $\mathrm{H}, \mathrm{NV}, \mathrm{HL}, \mathrm{NV}$ inv & TE, AT & - \\
\hline Fallah et al, $2009^{3}$ & $47 \mathrm{M}$ & - & $\mathrm{H}, \mathrm{NV}$ & TE, RT & - \\
\hline Furtado et al, $2009^{11}$ & $32 \mathrm{M}$ & 3 weeks & HNV, ataxia, B/L PE, CS & TE, AT & - \\
\hline Singh et al, $2011^{8}$ & $21 \mathrm{M}$ & 1 month & $\begin{array}{l}\mathrm{H}, \mathrm{NV} \text {, ataxia, B/L PE, } \\
\text { left VII, IX, X, CS }\end{array}$ & TE only & $\begin{array}{l}\text { Recurrence } \\
\text { and metastasis } \\
\text { at } 15 \text { months }\end{array}$ \\
\hline Spina et al, $2013^{12}$ & $22 \mathrm{M}$ & 3 months & $\begin{array}{l}\mathrm{H}, \mathrm{HL} \text {, ataxia, } \mathrm{L} \\
\text { Nystagmus }\end{array}$ & TE, RT & - \\
\hline Spina et al, $2013^{12}$ & $26 \mathrm{~F}$ & Chr H & $\begin{array}{l}\mathrm{H}, \mathrm{HL} \text {, ataxia, rt arm } \\
\text { weakness, L VII }\end{array}$ & TE, RT & - \\
\hline Bahrami et al, $2013^{7}$ & $23 \mathrm{M}$ & 2 months & HL, NV, ataxia & TE, RT & 12 months \\
\hline Goudihalli et al, $2016^{6}$ & $50 \mathrm{M}$ & 1 month & L VII, VIII, IX, X, H & $\begin{array}{l}\text { PE, abandoned due } \\
\text { to bleeding }\end{array}$ & Vegetative \\
\hline Present case, 2018 & $42 \mathrm{~F}$ & 2 months & $\mathrm{H}, \mathrm{NV}$, ataxia, left CS & TE, RT & 15 months \\
\hline
\end{tabular}

Abbreviations: AT, adjuvant therapy; B/L PE, bilateral papilledema; CPA, cerebellopontine angle; CS, cerebellar symptoms; $\mathrm{CT}$, chemotherapy; $\mathrm{H}$, headache; HA, hemianesthesia; HL, hearing loss; HP, hemiparesis; NV, nausea and vomiting; PE, partial excision; RT, radiotherapy; TE, total excision.

without any association with cerebellar tissue; however, subsequent histopathology report of medulloblastoma made our patients' case interesting and rare. After reviewing the literature, the 5 -year survival rate has been reported to be around $30 \%$ for medulloblastomas in this location after surgery and radiotherapy, ${ }^{1}$ while there have been cases that have improved with the use of combination chemotherapy such as vincristine-based regimens of chemotherapy. ${ }^{10} \mathrm{Few}$ cases have shown improvement with combination of chemotherapy and radiation therapy; however, surgery along with chemotherapy has remained the mainstay of treatment. So $\mathrm{far}$, there is no clear-cut consensus as to whether the CPA medulloblastomas are more aggressive compared with their vermian counterpart. ${ }^{6,14}$ We believe this may indicate a probable higher malignant potential of CPA medulloblastomas in comparison to their vermian counterpart. Surgery via the retromastoid route, followed by radiotherapy, remains the main treatment modality to manage these cases.

\section{Conclusion}

Over the years, medulloblastomas have shown a remarkable degree of heterogeneity in terms of their presentation, radiological diagnosis and biological behavior. Although considered to be a common pediatric intra-axial tumor, increasing solitary reports of it presenting extra-axially in CPA region mandates it to be included in the differential diagnosis of CPA tumors. This rare presentation at this unusual location may mislead its proper diagnosis and delay the required adjuvant therapy.

\section{Conflict of Interest}

None declared.

\section{References}

1 Chern JJ, Rao G, Lang FF, Medulloblastoma. In: Youmans JR ed., Neurological Surgery, 7th ed. Vol 2. Philadelphia, PA W.B. Saunders Company; 2011549

2 Bhaskar MK, Jaiswal M, Ojha BK, et al. Extra-axial cerebellopontine angle medulloblastoma in an infant. Pediatr Neurosurg 2017;52(2):122-126

3 Fallah A, Banglawala SM, Provias J, Jha NK. Extra-axial medulloblastoma in the cerebellopontine angle. Can J Surg 2009;52(4):E101-E102

4 Meghana C, Santosh P. An extraaxial cerebello-pontine angle medulloblastoma in a 56 year old male - a rare case report. Int J Sci Res 2016;5:822-823

5 Cugati G, Singh M, Symss NP, Pande A, Chakravarthy VM, Ramamurthi R. Extra-axial cerebello pontine angle medulloblastoma: a rare site of tumor. Indian J Med Paediatr Oncol 2011;32(2):123-124

6 Goudihalli SR, Pathak A, Brar R, Mundi I. Reappraisal of cerebellopontine angle medulloblastomas: Report of a fatal case and lessons learned. Interdisciplinary Neurosurg 2018;12:20-23

7 Bahrami E, Bakhti S, Fereshtehnejad SM, Parvaresh M, Khani MR. Extra-axial medulloblastoma in cerebello-pontine angle: A report of a rare case with literature review. Med J Islam Repub Iran 2014;28:57

8 Singh M, Cugati G, Symss NP, Pande A, Vasudevan MC, Ramamurthi R. Extra axial adult cerebellopontine angle medulloblastoma: an extremely rare site of tumor with metastasis. Surg Neurol Int 2011;2:25

9 Gil-Salú JL, Rodríguez-Peña F, López-Escobar M, Palomo MJ. Medulloblastoma presenting as an extra-axial tumor in the cerebellopontine angle [article in Spanish]. Neurocirugia (Astur) 2004;15(3):285-289

10 Becker RL, Becker AD, Sobel DF. Adult medulloblastoma: review of 13 cases with emphasis on MRI. Neuroradiology 1995;37(2):104-108 
11 Furtado SV, Venkatesh PK, Dadlani R, Reddy K, Hegde AS. Adult medulloblastoma and the "dural-tail" sign: rare mimic of a posterior petrous meningioma. Clin Neurol Neurosurg 2009;111(6):540-543

12 Spina A, Boari N, Gagliardi F. Franzin A, Terreni MR, Mortini P. Review of cerebellopontine angle medulloblastoma. $\mathrm{Br}$. J Neurosurg 2013;27(3):316-320
13 Jaiswal AK, Mahapatra AK, Sharma MC. Cerebellopointine angle medulloblastoma. J Clin Neurosci 2004;11(1):42-45

14 Kumar R, Achari G, Mishra A, Chhabra DK. Medulloblastomas of the cerebellopontine angle. Neurol India 2001;49(4):380-383

15 Akay KM, Erdogan E, Izci Y, Kaya A, Timurkaynak E. Medulloblastoma of the cerebellopontine angle-case report. Neurol Med Chir (Tokyo) 2003;43(11):555-558 